\title{
Photobilirubin II
}

\author{
Raymond BONNETT,* Dennis G. BUCKLEY, ${ }^{*}$ Dariush HAMZETASH,* Geoffrey E. HAWKES,* \\ Stella IOANNOU* and Mark S. STOLL $\dagger$ \\ *Department of Chemistry, Queen Mary College, Mile End Road, London E1 4NS, U.K., and \\ †Division of Clinical Chemistry, Clinical Research Centre, Watford Road, Harrow, Middx. HA1 3UJ, U.K.
}

(Received 23 January 1984/Accepted 9 March 1984)

\begin{abstract}
An improved preparation of photobilirubin II in ammoniacal methanol is described. Evidence is presented which distinguishes between the two structures proposed earlier for photobilirubin II in favour of the cycloheptadienyl structure. NuclearOverhauser-enhancement measurements with bilirubin IX $\alpha$ and photobilirubin II in dimethyl sulphoxide are complicated by the occurrence of negative and zero effects. The partition coefficient of photobilirubin II between chloroform and phosphate buffer ( $\mathrm{pH} 7.4)$ is 0.67 .
\end{abstract}

The irradiation of bilirubin IX $\alpha$ (1) with blue light in an inert atmosphere leads to photoisomerization to give products of two types: those that readily revert to the starting material, and those that do not. The first group consists of two components (photobilirubins IA and IB), which have not been isolated in a chemically pure state, partly because of their ready re-isomerization. There is now considerable evidence for the formulation of these substances as the $(4 E, 15 Z)$ and $(4 Z, 15 E)$-isomers of natural (i.e. $4 Z, 15 Z$-) bilirubin IX $\alpha$ (McDonagh et al., 1982a; Falk et al., 1982). The second group of isomers also consists of two components [photobilirubins IIA and IIB (Stoll et al., 1979); lumirubin and isolumirubin (McDonagh et al., 1982b)]. On the basis of n.m.r. measurements at high field (Stoll et al., 1982), it was concluded that in the formation of photobilirubin II the intramolecular cyclization of the C-3 vinyl group had occurred, to give a mixture of diastereoisomers. Several structures were considered: the available n.m.r. data were found to accord with two possible structures (2) and (3), but could not distinguish between them. Subsequently, each of these structures has been favoured (3; Onishi et al., 1982) or supported (2; McDonagh et $a l ., 1982 b$ ). The present paper provides evidence that eliminates structure (3), leaving (2) as the preferred structure.

Abbreviation used: n.O.e., nuclear Overhauser enhancement.

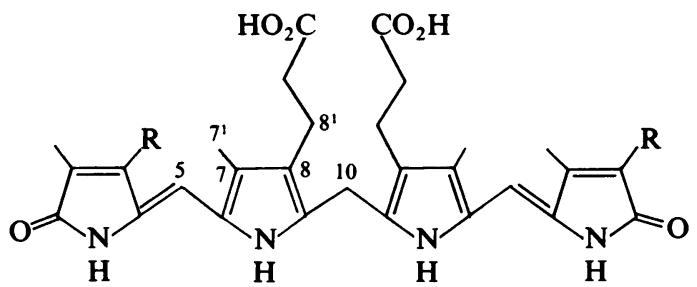

(1) $\mathrm{R}=$ vinyl, bilirubin IX $\alpha$

(4) $R=$ ethyl, mesobilirubin IX $\alpha$<smiles>C=CC1=C(C)/C(=C/c2[nH]c(CC3=C(CCC(=O)O)C4(C)CC=C5C(=CC4=N3)NC(=O)C5C)c(CCC(=O)O)c2[Al])NC1=O</smiles>

(2)<smiles></smiles>

(3) 


\section{Experimental}

\section{General methods}

A Waters M6000A pump with a UK6 injector was used, together with a Cecil CE212 detector set at $440 \mathrm{~nm}$. Yields quoted are spectroscopic and are based on $\varepsilon=45000 \mathrm{M}^{-1} \cdot \mathrm{cm}^{-1}$ at $\lambda_{\text {max. }}(429 \mathrm{~nm})$ for photobilirubin II in methanol and $\varepsilon=$ $60000 \mathrm{M}^{-1} \cdot \mathrm{cm}^{-1}$ at $\lambda_{\text {max. }}(453 \mathrm{~nm})$ for bilirubin in chloroform (Stoll et al., 1979). Phosphate buffer, $\mathrm{pH} 7.4$, was prepared from $\mathrm{KH}_{2} \mathrm{PO}_{4}(1.183 \mathrm{~g})$ and $\mathrm{Na}_{2} \mathrm{HPO}_{4}, 12 \mathrm{H}_{2} \mathrm{O}(5.249 \mathrm{~g})$ in glass-distilled water (1 litre). I.r.-absorption spectra were determined on a Perkin-Elmer model 257 instrument, and were calibrated with a polystyrene film. P.m.r. spectra were measured at $400 \mathrm{MHz}$ and $500 \mathrm{MHz}$ (Bruker WH-400 and AM-500 instruments) at approx. $25^{\circ} \mathrm{C}$. The technique for measuring n.O.e. difference spectra has been described elsewhere (Sanders \& Mersh, 1982), and percentage n.O.e. effects, which are regarded as subject to an error of about $25 \%$, were obtained by comparison of the integrals of the saturated and enhanced resonances in the difference spectrum.

\section{Photobilirubin II}

An improved preparation is as follows. All work-up procedures were carried out under subdued light, and methanolic solutions were concentrated without delay.

Bilirubin (100 mg) (Sigma Chemical Co.) in ammoniacal methanol $(76 \mathrm{~mm} ; 160 \mathrm{ml})$ was purged with argon (10 $\mathrm{min})$ and was then irradiated under argon with four $20 \mathrm{~W}$ blue-fluorescent lamps (Vickers Medical) for $2 \mathrm{~h}$. The solvent was removed at the rotatory evaporator (bath $50-60^{\circ} \mathrm{C}$ ), and the residue was triturated with methanol $(5 \mathrm{ml})$. The supernatant was decanted from bilirubin, filtered (glass-fibre paper, Whatman GF/A), and the solvent removed. The process of extraction with methanol was repeated (residue of largely unchanged bilirubin, $76 \mathrm{mg}$ ). The total residue from the evaporation of the two methanolic extracts was subjected to t.l.c. [Whatman PK6F silica gel, $0.5 \mathrm{~mm} \times 200 \mathrm{~mm} \times 200 \mathrm{~mm}$; two plates; eluted with chloroform/methanol/water $(40: 9: 1$, by vol.)]. A major yellow band at $R_{F}$ approx. 0.35 (photobilirubins IIA and IIB) was accompanied by a miscellany of components, mainly minor ones $\left(R_{F} 0.95\right.$, bilirubin, $6 \mathrm{mg} ; R_{F} 0.6-0.8$, photobilirubins IA and IB, collected as bilirubin, $5 \mathrm{mg} ; R_{F}$ 0.3 , green; $R_{F} 0.25$, biliverdin; $R_{F} 0.20$, yellow; $R_{F}$ 0.15 , violet; $R_{F} 0.10$, yellow, photobilirubin III). The band at $R_{F}$ approx. 0.35 was eluted with methanol, and rechromatographed on Whatman K6 silica gel $(0.25 \mathrm{~mm} \times 200 \mathrm{~mm} \times 200 \mathrm{~mm}$, two plates) with the same solvent system as before. The major yellow band was extracted with methanol, the suspension was filtered, and the photobilirubin II $(A+B)$ was determined spectroscopically $(4 \mathrm{mg}$, $4 \%$ yield, $31 \%$ conversion). The solvent was removed, and the yellow-brown amorphous photobilirubin II was used at once. It could be stored, with slow decomposition, under argon at $-25^{\circ} \mathrm{C}$. $\lambda_{\text {max. }}$ (methanol): $430 \mathrm{~nm} . m / z$ (fast-atom-bombardment mass spectrometry): $585(M+1)$. I.r. $(\mathrm{KBr}$ disc): 3380 (br.), 3280 (sh.), 1717 (sh.), 1675, 1640, $1575,1455,1410,1390,1265$ and $1200 \mathrm{~cm}^{-1}$.

\section{Irradiation of photobilirubin II}

Freshly purified photobilirubin II $(\mathbf{A}+\mathbf{B}$; $2.2 \mathrm{mg}$ ) in chloroform (distilled, $+1 \%$ ethanol; $50 \mathrm{ml}$ ) was irradiated under argon with four $20 \mathrm{~W}$ blue-fluorescent lamps (Vickers Medical) for $2 \mathrm{~h}$. The solvent was removed, and the residue was purified on one t.l.c. plate (Whatman K6; $0.15 \mathrm{~mm} \times 200 \mathrm{~mm} \times 200 \mathrm{~mm}$; solvent system as before). Three major bands were observed: $R_{F}$ 0.96 , bilirubin $\left[\lambda_{\max } .\left(\mathrm{CHCl}_{3}\right) 454 \mathrm{~nm} ; 0.6 \mathrm{mg}\right.$, $27 \%$ ]; $R_{F} 0.60$, violet compound of unknown structure; $R_{F} 0.35$, photobilirubin II $(0.55 \mathrm{mg}$, $25 \%$ ). Among a number of minor bands was a yellow substance with $R_{F} 0.10$ (photobilirubin III; Stoll et al., 1982), which on resubmission to t.l.c. was not distinguished from photobilirubin II.

The bilirubin formed in this photoreaction could not be distinguished by mixed high-pressure liquid chromatography or by several t.l.c. systems from the authentic bilirubin from which the photobilirubin II had been prepared. Conditions for highpressure liquid chromatography: $\mu$-Porasil $(30 \mathrm{~cm})$ eluted with light petroleum (b.p. $60-80^{\circ} \mathrm{C}$ )/chloroform/formic acid $(40: 20: 0.1$, by vol.) at $1 \mathrm{ml} / \mathrm{min}$, detector set at $440 \mathrm{~nm}$. Retention times: bilirubin III $\alpha, 6 \mathrm{~min}$; bilirubin IX $\alpha, 7.5 \mathrm{~min}$; bilirubin $X I I I \alpha, 9 \mathrm{~min}$. The original bilirubin used in the preparation of photobilirubin II was found in this way to contain approx. $2-3 \%$ of III $\alpha$ and XIII $\alpha$ isomers. The bilirubin formed by irradiating photobilirubin II contained virtually no bilirubin III $\alpha$ and approx. $3-5 \%$ of bilirubin XIII $\alpha$.

Conditions for t.l.c.: Merck Kieselgel 60F254, $0.2 \mathrm{~mm}$ thick, chloroform/ethyl acetate $(99: 1, \mathrm{v} / \mathrm{v})$, $R_{F} 0.55$ (III $\alpha$ and XIII $\alpha$ isomers not detected).

\section{Partition coefficients of bilirubin and photobilirubin II}

A freshly purified sample of photobilirubin II $(A+B)$ in methanol was adjusted to $100 \mathrm{ml}$, and the absorbance at $430 \mathrm{~nm}$ was recorded $(\varepsilon=$ $45000 \mathrm{M}^{-1} \cdot \mathrm{cm}^{-1}$; Stoll et al., 1979). The solvent was removed almost completely, and the residue was adjusted to $100 \mathrm{ml}$ with phosphate buffer, $\mathrm{pH} 7.4$, and the absorbance at the $\lambda_{\text {max. }}(429 \mathrm{~nm})$ was recorded. The average of four experiments gave $\varepsilon=43000 \mathrm{M}^{-1} \cdot \mathrm{cm}^{-1}$ at $\lambda_{\max .}(429 \mathrm{~nm})$ at pH 7.4. 
The phosphate buffer solution was extracted with an equal volume of chloroform $\left(25-29^{\circ} \mathrm{C}\right.$, vigorous shaking for $2 \mathrm{~min}$ ), which became yellow. The layers were separated and filtered, and absorbances were measured at $430 / 429 \mathrm{~nm}$. The partition coefficient for photobilirubin II, $[\mathrm{PBII}]_{\mathrm{CHCl}_{3}} /[\mathrm{PBII}]_{\text {buffer, }}$ was 0.67 . When a similar experiment was carried out for bilirubin (but starting with the pigment dissolved in the chloroform), there was no appreciable increase in absorption at $440 \mathrm{~nm}$ in the aqueous phase, indicating that the partition coefficient, $[\mathrm{BR}]_{\mathrm{CHCl}_{3} /}$ $[B R]_{\text {buffer }}$, had a value that was immeasurably large under the conditions employed.

\section{Results and discussion}

The preparation of photobilirubin II has been improved by carrying out the irradiation of bilirubin IX $\alpha$ (1) in ammoniacal methanol. Although the yield has been doubled, it remains small $(4 \% ; 31 \%$ conversion), and the product is difficult to handle. It has not been obtained crystalline, and gradually polymerizes. Under the conditions of our experiment $\left(\lambda_{\text {max., irradiation }} 440 \mathrm{~nm}, 80 \mathrm{~W}, 2 \mathrm{~h}\right)$, photoaddition of methanol to the exo-vinyl group [for which the reaction conditions ( $\lambda_{\text {irradiation }}$ $>300 \mathrm{~nm}, 125 \mathrm{~W}, 30 \mathrm{~h}$ ) are described (Manitto, 1971)] was not detected by t.l.c. A range of minor products was formed during the irradiation, however. These probably arise from the vinyl group(s), since, when mesobilirubin (4) was irradiated under the same conditions, the reaction mixture contained few by-products. The major products with mesobilirubin are presumed to be components of the photoisomer I type [i.e. the $(4 Z, 15 E)$ - and $(4 E, 15 Z)$-isomers (4)], since they reverted to mesobilirubin on two-dimensional t.l.c. No product corresponding to polarity to photobilirubin II was detected.

The mass spectrum of photobilirubin II, with use of the fast-atom-bombardment technique, gave the molecular ion, $(M+1)^{+}$, at $m / z 585$, confirming the observations reported by Stoll et al. (1979). However, in the earlier work (Stoll et al., 1979), an i.r.-absorption spectrum of photobilirubin II was given that showed a peak at approx. $1740 \mathrm{~cm}^{-1}$ : this absorption might reasonably be assigned to the $\delta$-lactone in structure (3). We have now repeated the i.r.-absorption observation several times, and, although the carbonyl band at $1675 \mathrm{~cm}^{-1}$ is broadened on its higher-energy side, we have not detected a peak in the $1740 \mathrm{~cm}^{-1}$ region. We conclude that structure (3) is not tenable, and note that, with four chiral centres, it offers stereoisomeric possibilities much more numerous (i.e. 16) than have actually been encountered so far with photobilirubin II.
Table 1. N.O.e. effects for photobilirubin II in $\left[{ }^{2} \mathrm{H}_{6}\right]$ dimethyl sulphoxide $\left(400 \mathrm{MHz}, 25^{\circ} \mathrm{C}, 1.8-2.0 \mathrm{mg}\right.$ in $\left.0.7 \mathrm{ml}\right)$

\begin{tabular}{lcccc} 
Nucleus & \multicolumn{4}{c}{ N.O.e. $(\%)$} \\
\cline { 2 - 5 } $\begin{array}{c}\text { irradiated } \\
\mathrm{H}-13^{1}(2.05 \delta)\end{array}$ & $\mathrm{H}-13^{1}$ & $\mathrm{H}-17^{1}$ & $\mathrm{H}-15$ & $\mathrm{H}-18^{1}$ \\
$\mathrm{H}-17^{1}(2.15 \delta)$ & 0 & 0 & -5.5 & 0 \\
$\mathrm{H}-15(6.03 \delta)$ & -1.1 & -1.7 & -6.3 & -2.4 \\
\end{tabular}

Hence, by elimination, photobilirubin II is formulated as structure (2), the two isomers being the two diastereoisomers (each an enantiomeric pair) involving the chiral centres at $\mathrm{C}-2$ and $\mathrm{C}-7$. In accord with this conclusion, two signals $(\delta 12.00$ and 12.22 p.p.m.), assigned to different carboxylic acid protons, have been observed in the n.m.r. spectrum of a sample of photobilirubin II dissolved in $\left[{ }^{2} \mathrm{H}_{6}\right]$ dimethyl sulphoxide.

We had hoped to test structure (2) by the use of n.O.e. difference spectroscopy (Sanders \& Mersh, 1982): this has given only partial success, although it has revealed a rather curious effect. For photobilirubin II in $\left[{ }^{2} \mathbf{H}_{6}\right]$ dimethyl sulphoxide negative n.O.e. effects (Table 1) were detected on irradiating the protons of methyl groups at C-13 and $\mathrm{C}-17$ and the methine proton at $\mathrm{C}-15$. However, no n.O.e. effects were observed from the left-hand part of the structure. The observation of negative effects was at first surprising, in view of the positive effects found by Kaplan \& Navon (1981) in their study at $90 \mathrm{MHz}$ of mesobilirubin, bilirubin and bilirubin dimethyl ester in $\left[{ }^{2} \mathrm{H}\right]-$ chloroform solutions. Accordingly, we repeated some n.O.e. experiments on bilirubin IX $\alpha$ in both $\left[{ }^{2} \mathrm{H}\right]$ chloroform and dimethyl sulphoxide solutions. The results (Table 2) show a change in the sign of the n.O.e. effect from positive to negative on changing the solvent from $\left[{ }^{2} \mathrm{H}\right]$ chloroform to dimethyl sulphoxide. Such a change in n.O.e. behaviour can result from an increase in the correlation time for molecular re-orientation (see, e.g., Noggle \& Schirmer, 1971) in dimethyl sulphoxide, probably because of its greater solvating power and viscosity. Indeed, Kaplan \& Navon (1981) estimate correlation times for mesobilirubin in $\left[{ }^{2} \mathrm{H}\right]$ chloroform and dimethyl sulphoxide solutions at $30^{\circ} \mathrm{C}$ to be $0.59 \times 10^{-10}$ and $2.2 \times 10^{-10} \mathrm{~s}$ respectively.

The lack of detectable n.O.e. effects for the lefthand part of photobilirubin II might be rationalized if this part of the molecule were less associated with the solvent dimethyl sulphoxide, consequently having a somewhat greater degree of internal mobility. The n.O.e. effects that were observed support the $15 Z$ geometry shown in structure (2), and in addition the n.O.e. at $18^{1}-\mathrm{H}$ 
Table 2. N.O.e. effects for bilirubin IX $\mathrm{X}$ in $\left[{ }^{2} \mathrm{H}\right]$ chloroform and $\left[{ }^{2} \mathrm{H}_{6}\right]$ dimethyl sulphoxide $\left(400 \mathrm{MHz}, 25^{\circ} \mathrm{C}\right)$

(i) [ $\left.{ }^{2} \mathrm{H}\right] \mathrm{Chloroform}(0.5 \mathrm{mg}$ in $0.8 \mathrm{ml})$

\begin{tabular}{lcccc} 
Nucleus & \multicolumn{4}{c}{ N.O.e. $(\%)$} \\
\cline { 2 - 5 } irradiated & $\mathrm{H}^{-13^{1}}$ & $\mathrm{H}-7^{1}$ & $\mathrm{H}-17^{1}$ & $\mathrm{H}-18^{2}$ \\
$\mathrm{H}-5(6.13 \delta)$ & 2.4 & 0 & 1.1 & $8.1^{*}$ \\
& 0 & 2.9 & 0 & 0
\end{tabular}

(ii) $\left[{ }^{2} \mathrm{H}_{6}\right]$ Dimethyl sulphoxide $(2 \mathrm{mg}$ in $1.0 \mathrm{ml})$

$\begin{array}{cccccc}\begin{array}{c}\text { Nucleus } \\ \text { irradiated }\end{array} & \overbrace{\mathrm{H}-7^{1}} & \mathrm{H}-13^{1} & \mathrm{H}-17^{1} & \mathrm{H}-5,15 & \mathrm{H}-3^{1} \\ \mathrm{H}-7^{1}(2.02 \delta) \dagger & - & 0 & 0 & -3.4 & 0 \\ \mathrm{H}-13^{1}(2.05 \delta) \dagger & 0 & - & 0 & -4.6 & 0 \\ \mathrm{H}-17^{1}(2.18 \delta) & 0 & 0 & - & -4.3 & 0 \\ \mathrm{H}-5,15(6.10 \delta) & -2.6 & -1.6 & -2.4 & - & -11.4\end{array}$

* This arises because of the effective coincidence of the resonances for $\mathrm{H}-15$ and the other $\mathrm{H}-18^{2}$ proton (see Defoin-Straatmann et al., 1982).

† These two resonances are sufficiently close that saturation of one produced partial saturation of the other.

(but not at the $18^{2}-\mathrm{H}$ protons) on irradiation of the C-17 methyl group suggests the extended conformation for the vinyl substituent as shown (i.e. s-trans to the 17,18-double bond). Attempts to obtain n.O.e. measurements for photobilirubin II in other solvents were thwarted by lack of solubility ( $\left[{ }^{2} \mathrm{H}\right]$ chloroform) or by decomposition of the sample during the lengthy observation periods required $\left(\left[{ }^{2} \mathrm{H}_{4}\right]\right.$ methanol). Falk et al. (1982) were successful in observing (presumably positive) n.O.e. effects in their study of 'photobilirubin' [i.e. photobilirubin IA/IB; $4 E, 15 Z(4 Z, 15 E)$-bilirubin] in $\left[{ }^{2} \mathrm{H}_{4}\right]$ methanol solution but comment on 'disturbing solvent effects on the n.O.e. measurement' when dimethyl sulphoxide $/\left[{ }^{2} \mathrm{H}\right]$ chloroform mixtures were used.

In view of the doubt expressed elsewhere (McDonagh et al., 1982b), we have repeated the irradiation of photobilirubin II (Stoll et al., 1982). In our hands this gives starting material, bilirubin and photobilirubin III. The bilirubin was shown by high-pressure liquid chromatography to be essentially the IX $\alpha$ isomer: a small proportion of the XIII $\alpha$ isomer was observed, but no III $\alpha$ isomer was detected in our experiments. The photobilirubin III reverted to photobilirubin II on rechromatography, and is plausibly formulated (Stoll et al., $1982)$ as the (15E)-isomer of (2).

The behaviour on t.l.c. shows clearly that the polarity of the substances considered here increases in the series bilirubin $<$ photobilirubin I $<$ photobilirubin II $<$ photobilirubin III. Photobili- rubin II appears to have been found in the bile of jaundiced newborn infants after irradiation (Onishi et al., 1980). To some degree the excretion of the photoproducts is likely to be related to watersolubility, and we have therefore measured partition coefficients between chloroform and phosphate buffer, $\mathrm{pH} 7.4$, for the more stable members of this series. For bilirubin the concentration in the aqueous phase is extremely small, and not measurable in our experiment. The true solubility of bilirubin in $\mathrm{pH} 7.4$ buffer has been estimated to be not more than $0.1 \mu \mathrm{M}$ (see McDonagh, 1979), and is probably much lower. In contrast, photobilirubin II is appreciably soluble in the pH7.4 buffer, and, indeed, favours the aqueous phase over the organic solvent employed.

Ignoring aggregation effects, the apparent partition coefficient, [PBII $]_{\mathrm{CHCl}_{3}} /[\mathrm{PBII}]_{\text {buffer }}$, was 0.67 . The enhanced water-solubility is attributed to the decreased opportunity for intramolecular hydrogen-bonding, and the increased basicity of $\mathrm{N}-22$, in photobilirubin II in comparison with bilirubin.

N.m.r. spectra (n.O.e.) were recorded at Queen Mary College on the ULIRS WH-400 spectrometer and, by courtesy of Dr. J. Feeney, on the AM-500 spectrometer at Mill Hill. We are grateful to Mr. M. J. Buckingham for his help with the n.O.e. experiments. The support of the Medical Research Council is gratefully acknowledged.

\section{References}

Defoin-Straatmann, R., Defoin, A., Kuhn, H. J. \& Schaffner, K. (1982) Liebigs Ann. Chem. 1759-1765

Falk, H., Muller, N., Ratzenhofer, M. \& Winsauer, K. (1982) Monatsch. Chem. 113, 1421-1432

Kaplan, D. \& Navon, G. (1981) J. Chem. Soc. Perkin Trans. 2 1874-1883

Manitto, P. (1971) Experientia 27, 1147-1149

McDonagh, A. F. (1979) in The Porphyrins (Dolphin, D., ed.), vol. 6, pp. 293-491 (p. 316 in particular), Academic Press, New York

McDonagh, A. F., Palma, L. A., Trull, F. R. \& Lightner, D. A. (1982a) J. Am. Chem. Soc. 104, 6865-6867

McDonagh, A. F., Palma, L. A. \& Lightner, D. A. (1982b) J. Am. Chem. Soc. 104, 6867-6869

Noggle, J. H. \& Schirmer, R. E. (1971) The Nuclear Overhauser Effect-Chemical Applications, Academic Press, New York

Onishi, S., Isobe, K., Itoh, S., Kawade, N. \& Sugiyama, S. (1980) Biochem. J. 190, 533-536

Onishi, S., Itoh, S., Isobe, K., Togari, H., Kitoh, H. \& Nishimura, Y. (1982) Pediatrics 69, 273-276

Sanders, J. K. M. \& Mersh, J. D. (1982) Prog. Nucl. Magn. Reson. Spectrosc. 15, 353-400

Stoll, M. S., Zenone, E. A., Ostrow, J. D. \& Zarembo, J. E. (1979) Biochem. J. 183, 139-146

Stoll, M. S., Vicker, N., Gray, C. H. \& Bonnett, R. (1982) Biochem. J. 201, 179-188 